\title{
Study on an Axial Flow Hydraulic Turbine with Collection Device
}

\author{
Yasuyuki Nishi, ${ }^{1}$ Terumi Inagaki, ${ }^{1}$ Kaoru Okubo, ${ }^{2}$ and Norio Kikuchi ${ }^{3}$ \\ ${ }^{1}$ Department of Mechanical Engineering, Ibaraki University, 4-12-1 Nakanarusawa-cho, Hitachi-shi, Ibaraki 316-8511, Japan \\ ${ }^{2}$ Graduate School of Science and Engineering, Ibaraki University, 4-12-1 Nakanarusawa-cho, Hitachi-shi, Ibaraki 316-8511, Japan \\ ${ }^{3}$ Ibasei, Ltd., 4-7-10 Kamine-cho, Hitachi-shi, Ibaraki 317-0064, Japan \\ Correspondence should be addressed to Yasuyuki Nishi; y-nishi@mx.ibaraki.ac.jp
}

Received 28 February 2014; Revised 16 May 2014; Accepted 18 May 2014; Published 22 July 2014

Academic Editor: Terrence W. Simon

Copyright (c) 2014 Yasuyuki Nishi et al. This is an open access article distributed under the Creative Commons Attribution License, which permits unrestricted use, distribution, and reproduction in any medium, provided the original work is properly cited.

\begin{abstract}
We propose a new type of portable hydraulic turbine that uses the kinetic energy of flow in open channels. The turbine comprises a runner with an appended collection device that includes a diffuser section in an attempt to improve the output by catching and accelerating the flow. With such turbines, the performance of the collection device, and a composite body comprising the runner and collection device were studied using numerical analysis. Among four stand-alone collection devices, the inlet velocity ratio was most improved by the collection device featuring an inlet nozzle and brim. The inlet velocity ratio of the composite body was significantly lower than that of the stand-alone collection device, owing to the resistance of the runner itself, the decreased diffuser pressure recovery coefficient, and the increased backpressure coefficient. However, at the maximum output tip speed ratio, the inlet velocity ratio and the loading coefficient were approximately $31 \%$ and $22 \%$ higher, respectively, for the composite body than for the isolated runner. In particular, the input power coefficient significantly increased (by approximately 2.76 times) owing to the increase in the inlet velocity ratio. Verification tests were also conducted in a real canal to establish the actual effectiveness of the turbine.
\end{abstract}

\section{Introduction}

Recently, the use of renewable forms of energy, such as sunlight, wind power, hydraulic power, and biomass, has attracted considerable attention. Because hydraulic power has high energy density with comparatively small fluctuation, it is a stable source of energy. Nevertheless, as with other types of renewable energy, it is relatively small-scale and limited to a particular region. Ideally, hydraulic power is developed according to specifications and applications with consideration of the surrounding environment.

The hydraulic turbines that are used to generate electrical power using waterpower are broadly classified into turbines for pipe conduits and turbines for open channels. Turbines for pipe conduits store water in dams and water tanks, and move the water using the stored potential energy. Hence, the number of construction sites with sufficient head of water and little impact on the ecosystem is small. On the other hand, turbines for open channels [1-3] do not require ancillary facilities for water transmission, and it is possible to generate power with a small head of water. However, diversion weirs are often necessary with such hydraulic turbines, which tend to be large because their rotational speed is low. In addition, as the turbines are fixed to a particular location, there are various installation-related constraints. Recently, despite the development of turbines that can generate power simply by being placed in the path of flow [4-6], the available turbine output power per unit water-receiving area is inadequate.

Thus, in this study, without resorting to the use of diversion weirs, we propose a new type of portable openchannel hydraulic turbine that uses the kinetic energy of the flow in the open channels of rivers and canals. The proposed turbine applies the principle of a diffuser wind turbine [7] with an attached brim and attempts to improve the output by catching and accelerating the flow using a collection device with a diffuser section, which is appended to an axial-flow runner. Open and shallow water channels are constrained in the height direction. Accordingly, the type described here 
differs from conventional wind turbines [7-11] and hydraulic turbines [12-15] in which the diffuser section of the collection device is constant vertically and varies horizontally. Thus, the outer diameter of the runner is almost as large as the water depth. Moreover, because a high-speed rotationtype runner is adopted, downsizing and weight savings are achieved, which is advantageous in terms of matching it to the generator. The proposed hydraulic turbine can generate power by simply being placed in the flow; moreover, it has excellent portability and small impact on ecosystems, and there are few constraints on the installation site.

In this paper, to develop an axial-flow turbine with such a collection device, we investigated the turbine performance characteristics and the flow field for various stand-alone collection devices using numerical analysis. Therefore, we investigated composite bodies with the collection device appended to the runner and the runner on its own. In addition, we performed verification tests in a real canal to investigate the effectiveness of the proposed hydraulic turbine.

\section{The New Hydraulic Turbine}

A schematic of the new type of open-channel turbine is shown in Figure 1, and that of the coordinate system is in Figure 2. The turbine uses the principles of the diffuser wind turbine [7] with an attached brim and comprises a collection device (C.D.) appended to an axial-flow runner. The turbine was designed assuming a flow speed $v_{\infty}$ of $1.5 \mathrm{~m} / \mathrm{s}$ and openchannel installation in water depth of $400 \mathrm{~mm}$.

An overview of the runner is shown in Figure 3, and the basic forms of the four different types of collection device (C.D.) are shown in Figures 4(a)-4(d). The runner is an axial-flow runner with an outer diameter of $380 \mathrm{~mm}$ and with the three blades and its design was based on the blade element momentum theory. To increase the output power to maximum, the outer diameter for the runner was increased to almost match the design water depth. Emphasizing the importance of strength when water flow is considered, MEL021 [16] was adopted for the airfoil of the blade, which has a maximum blade thickness relative to the chord length. The design angle of attack is $5^{\circ}$. We also note that the Reynolds number for maximum output tip speed ratio, based on the circumferential velocity of the tip and the runner radius, is approximately $2.1 \times 10^{6}$.

Type B, C, and D collection devices have an identical diffuser section, which varies depending on the presence or absence of an inlet nozzle and a brim. As the height direction is constrained by the depth of the water, the brim in type $\mathrm{D}$ is only on the right and left side of the collection device output. In addition, the height direction of the diffuser (the $z$ direction) is fixed while being expanded in the horizontal direction (the $y$ direction). Thus, it is possible to make the runner outer diameter almost as large as the water depth by making the height of the diffuser section the same as the water depth. The height of the diffuser section was $400 \mathrm{~mm}$ to match the design water depth and the spread angle was $8.1^{\circ}$. Note that the inlet and outlet are formed from nozzle

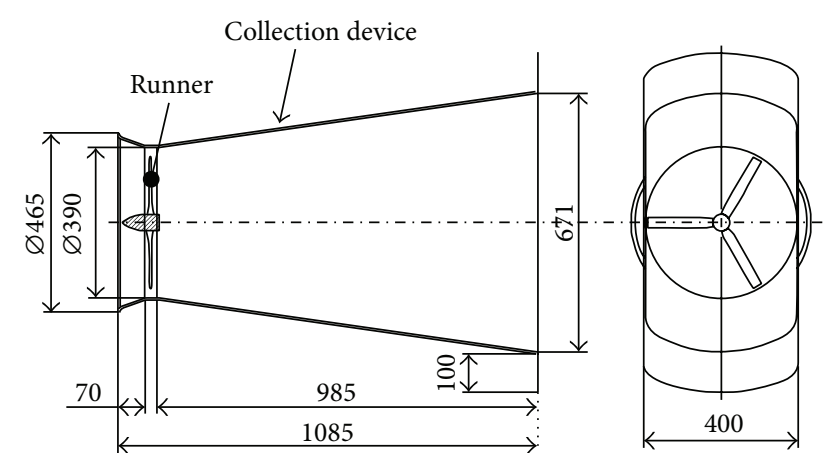

Figure 1: Hydraulic turbine.

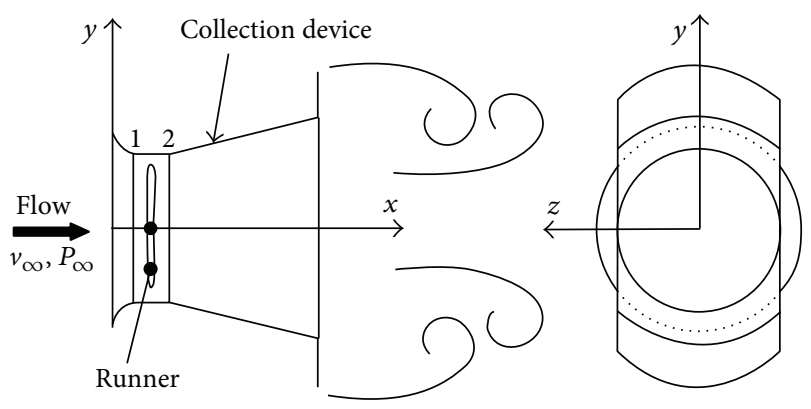

Figure 2: The definition of a coordinate system.

type (type A) and diffuser type (type B) collection devices, respectively.

\section{Numerical Analysis Method}

The general-purpose thermal fluid analysis code ANSYS CFX14.5 was used. A three-dimensional steady flow analysis was performed for the runner on its own, the collection device on its own, and the composite body comprising the runner and the collection device together. The basic equations are the conservation of mass equation and the conservation of momentum equation, and the SST (Shear Stress Transport) model was used as the turbulence model. The working fluid was water. For example, the model for the composite body comprising a runner and a collection device (Type D) is shown in Figure 5 and the total computational region in Figure 6. The latter comprises the following individual elements: the calculation object (the runner or the collection device or their respective composite bodies), the middle region, and the external region. To assess the potential performance of each calculation object, we assumed uniform flow entering the extensive space (external region), in which the calculation object has been placed. Obviously, the effect of free surface and velocity distribution in the open channel is not considered. The external region is cylindrical with a diameter 10 times the outer diameter of the runner. Moreover, the lengths upstream and downstream are 10 times and 15 times the length of the outer diameter of the runner, respectively, and are measured from the center of the runner. The computational grid consists of about 2.92 million elements for the runner, about 2.35 million elements for the 


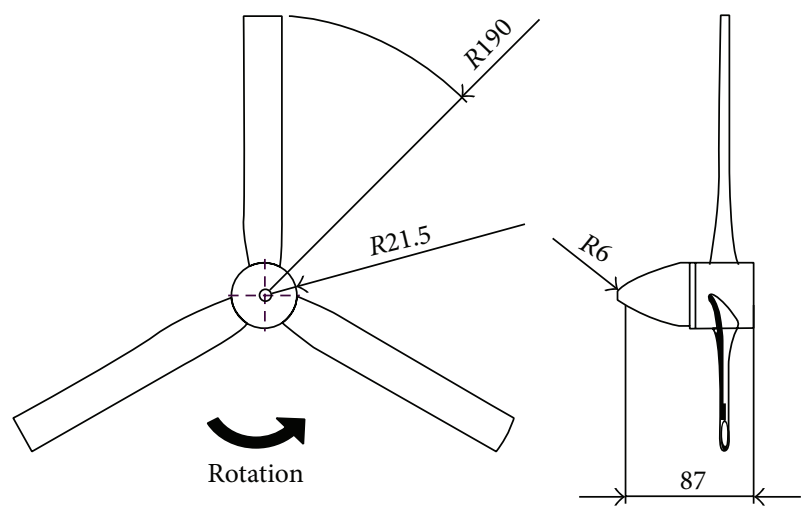

Figure 3: Runner.

collection device, and about 3.67 million elements for the composite body of the runner and the collection device. To investigate grid dependence, the number of computational grids of the composite body was increased by 1.5 times, and analysis was conducted at $\lambda=6.5$. Although the torque increased by only $5.1 \%$ from the result presented in this paper, the effect of computational grid number was comparatively small. The boundary conditions were velocity $v_{\infty}$ of $1.5 \mathrm{~m} / \mathrm{s}$ at infinite distance for the inlet boundary condition, the rotational speed for the runner, and a static pressure of $0 \mathrm{~Pa}$ for the outlet boundary. For wall surface boundaries, the outer periphery of the external region was assigned as the slip condition and the other wall surfaces as nonslip. Furthermore, for the analysis of the runner and for the runner and the collection device together, the boundaries of the rotation and the static systems were joined using the frozenrotor technique [17].

\section{Analysis Result and Discussion}

4.1. Performance Characteristics for the Collection Device on Its Own. The distribution of the velocity ratio $v_{a} / v_{\infty}$ in the $x$ direction for each of the collection devices is shown in Figure 7, and the performance parameters of the collection devices are summarized in Table 1. The average flow rate in the channel cross-section was used in $v_{a}$ for a given $x$ direction position. The value of $\overline{v_{a 1}}$ used in the inlet velocity ratio $K$ was the value at $x / x_{l}=0$ for type $\mathrm{A}$ and type $\mathrm{B}$, whereas the value at $x / x_{l}=0.08$ was used in type $\mathrm{C}$ and type D. Comparing types A and B, $v_{a} / v_{\infty}$ increased with increasing $x / x_{l}$ for the type A nozzle. In contrast, $v_{a} / v_{\infty}$ decreased for the type B diffuser. However, although $v_{a} / v_{\infty}<$ 1.0 even for $x / x_{l}=1.0$ with type A, $v_{a} / v_{\infty}=1.290$ for $x / x_{l}$ $=0(K=1.290)$ with type B. Consequently, the speed-up effect is achieved at the inlet of the type $B$ collection device. The static pressure distribution for the collection devices is shown in Figures 8(a)-8(d) and the streamlines in Figures 9(a)-9(d). It can be seen that the static pressure increases near the inlet of type $A$ and hinders the flow from entering the collection device. On the other hand, the static pressure near the inlet of type $B$ decreases and the flow is easily drawn into the collection device [8]. However, in type B, backflow is created inside the collection device. Furthermore, in the
TABLE 1: Performance parameters of different collection devices.

\begin{tabular}{lccc}
\hline & $C_{\mathrm{pd}}$ & $C_{\mathrm{pb}}$ & $K$ \\
\hline Type A & -2.274 & 0.135 & 0.513 \\
Type B & 0.365 & -0.221 & 1.290 \\
Type C & 0.713 & -0.171 & 1.926 \\
Type D & 0.720 & -0.555 & 2.241 \\
\hline
\end{tabular}

case of type $\mathrm{C}$ with an appended inlet nozzle, the backflow is not apparent. This is attributed to, as it can be seen from the streamlines, the smooth flow owing to the presence of the inlet nozzle [8]. The diffuser pressure recovery coefficient $C_{\mathrm{pd}}$ was significantly greater than that for type B and the value of $K$ for type $C$ increased 1.49 times compared with type $\mathrm{B}$. The comparison of types $\mathrm{C}$ and $\mathrm{D}$ reveals that $C_{\mathrm{pd}}$ is generally the same for both. However, the backpressure coefficient $C_{\mathrm{pb}}$ greatly decreased for type $\mathrm{D}$ to approximately one-third that for type $\mathrm{C}$. In contrast, type $\mathrm{D}$ has the largest value for $K=2.241$, increasing to about 1.16 times that for type C. Separation vortexes were formed behind the brim in type $\mathrm{D}$ and the static pressure dropped at the outlet of the collection device $[7,8]$. For this reason, the static pressure around the collection device inlet also decreased significantly, which presumably facilitated the flow to enter the collection device.

4.2. Performance Characteristics for the Runner and for the Runner and Collection Device. The correlation between the tip speed ratio $\lambda$ and the power coefficient $C_{W}$ for the runner and for the composite body comprising the runner and collection device is shown in Figure 10. We used type D, which has the best performance, as the collection device. Here, the pressure and the wall shear stress acting on the blade surface were multiplied by the radius and integrated to obtain the torque. The maximum value of $C_{W}$ for the runner is 0.191 for $\lambda=5.0$. On the other hand, the maximum value of $C_{W}$ for the composite body of the runner and collection device is 0.527 for $\lambda=6.5$. Therefore, when appending the collection device to the runner, the maximum value for $C_{W}$ shifts to high tip speed ratio values, and we see an increase to about 2.76 times the value for the runner. Below, we investigate the power increase that is attributable to the collection device.

The power coefficient $C_{W}$ and the input power coefficient $C_{I}$ are obtained by the following equations [7]:

$$
\begin{gathered}
C_{W}=\frac{W}{\rho A v_{\infty}^{3} / 2}=\eta C_{I} \\
C_{I}=\frac{\left(\overline{P_{1}}-\overline{P_{2}}\right) Q}{\rho A v_{\infty}^{3} / 2}=\psi K^{3}\left(1-\nu^{2}\right),
\end{gathered}
$$

where $\eta$ is the turbine efficiency, $\nu$ is the hub ratio, and $\psi$ is the loading coefficient.

In Figures 11-14, the correlation between the tip speed ratio $\lambda$ and each of the following parameters is shown: turbine efficiency $\eta$, the input power coefficient $C_{I}$, the loading coefficient $\psi$, and the inlet velocity ratio $K$. In Figure 11, we can see the value of $\lambda$ for which either $\eta$ is maximum for 


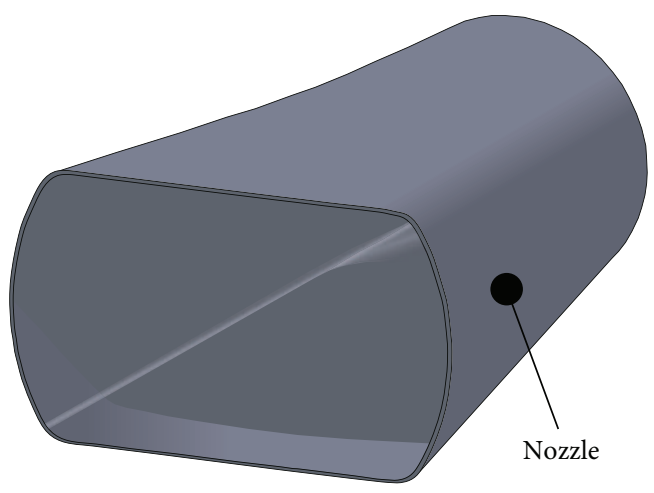

(a) Type A

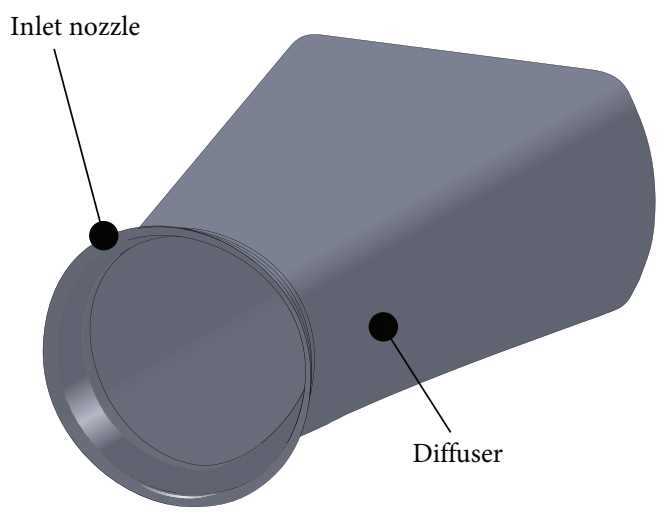

(c) Type C

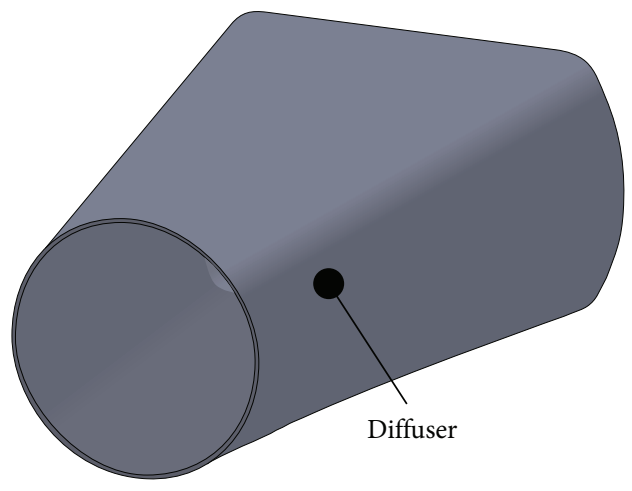

(b) Type B

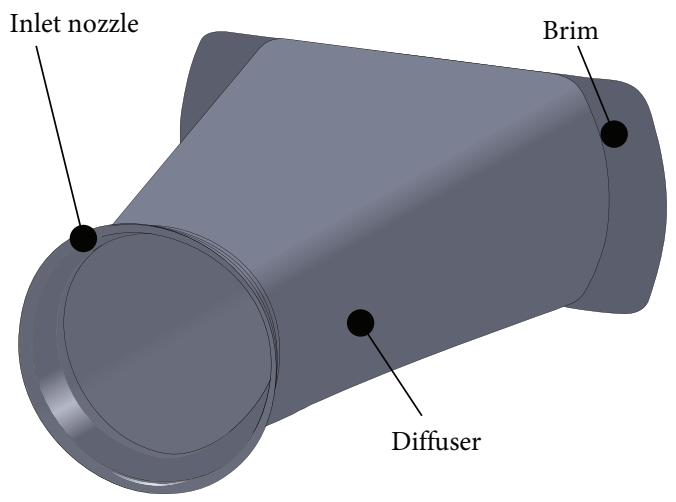

(d) Type D

Figure 4: Collection devices.

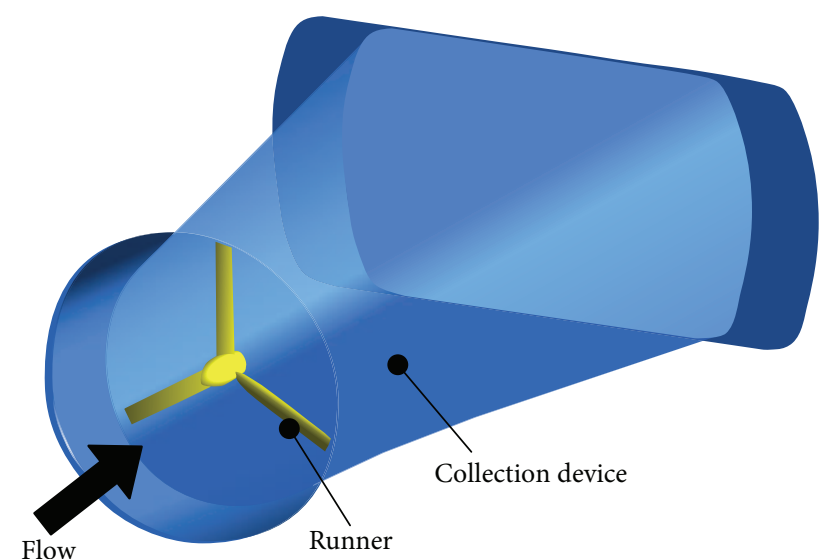

FIGURE 5: Computational model.

the runner or the composite body is slightly toward the low tip speed ratios compared with the value of $\lambda$ for which $C_{W}$ is maximum. For the runner, $\eta=0.477$ for $\lambda=5.0$, whereas for the composite body $\eta=0.477$ for $\lambda=6.5$, that is, almost the same. Radial distributions of the axial component of the absolute velocity at the runner inlet are plotted in Figure 15 . Here, $v_{a}$ at each radius is the average velocity along a $1 \mathrm{~mm}$ radius circumference upstream from the runner inlet. In Figure 15, we observe that the distributions of $v_{a} / u_{t}$ of the maximum-output tip speed ratios largely agree between

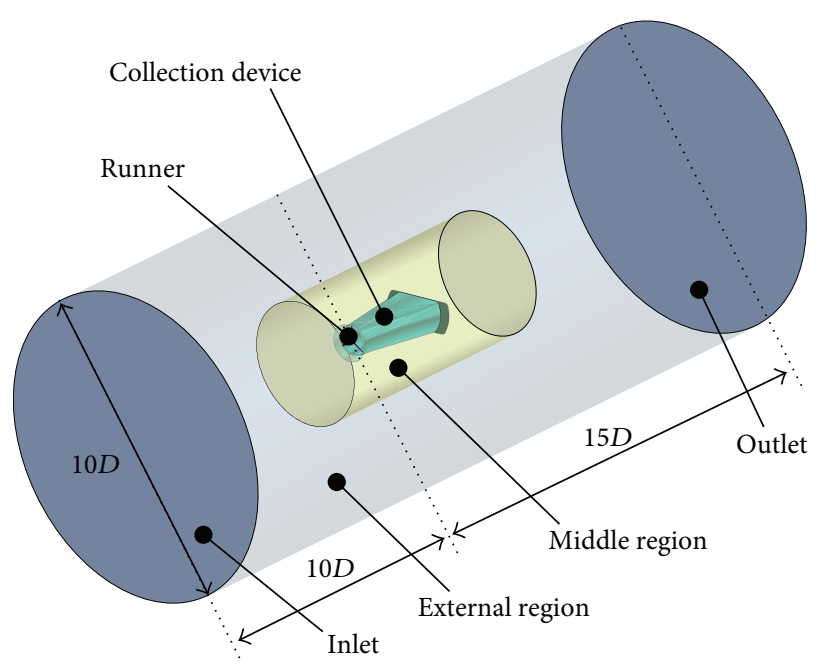

FIgURE 6: Computational domain.

the runner and the composite body. Therefore, the turbine efficiencies at both maximum-output tip speed ratios appear to be almost identical. However, the $v_{a} / u_{t}$ distributions of the composite body are slightly less uniform than those of the runner. On the other hand, in Figure 12, we see that for either the runner or the composite body, $C_{I}$ increases as $\lambda$ increases. For the runner, $C_{I}$ is 0.400 at $\lambda=5.0$; for the composite body, $C_{I}$ is 1.104 at $\lambda=6.5$. Therefore, $C_{I}$ is approximately 


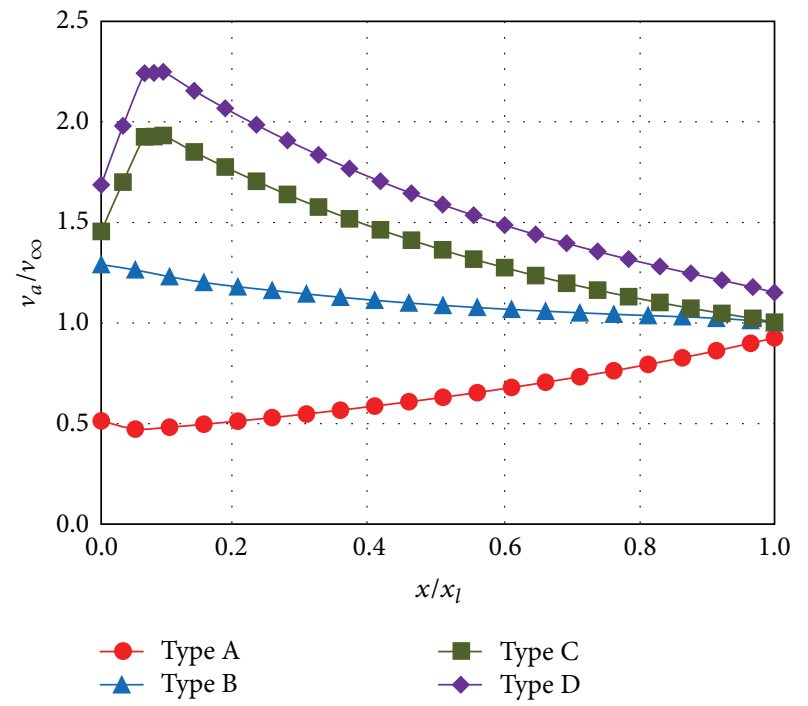

FIgURE 7: Velocity ratio distributions.

2.76 times higher for the composite body than for the runner on its own. Therefore, the increase in the power coefficient of the composite body can be attributed to the increase in the input power coefficient. Moreover, from Figure 13, $\psi=0.603$ for $\lambda=5.0$ for the runner and $\psi=0.733$ for $\lambda=6.5$ for the composite body, meaning that $\psi$ for the composite body has increased by approximately $21.5 \%$. Nevertheless, the increase in $\psi$ does not contribute significantly to the increase in the input power coefficient of the composite body, which is 2.76 times that of the runner. From Figure 14, it is apparent that, for either the runner or the composite body, $K$ behaves opposite to $\psi$ and decreases with increasing $\lambda$. For the runner, $K=0.872$ for $\lambda=5.0$ and for the composite body $K=$ 1.146 for $\lambda=6.5$; that is, $K$ has increased approximately 1.31 times. The input power coefficient increases proportionally to the cube of the abovementioned increase. Therefore, the significant increase in the input power coefficient with the composite body is primarily due to the increase in the inlet velocity ratio. Nonetheless, compared with $K=2.241$ for the collection device, $K$ for the composite body has decreased significantly. This point is investigated below.

The inlet velocity ratio $K$ is expressed with the following equation [7]:

$$
K=\frac{\overline{v_{a 1}}}{v_{\infty}}=\sqrt{\frac{1-C_{\mathrm{pb}}}{1-f C_{\mathrm{pd}}+\psi}},
$$

where $f$ is the correction coefficient that is less than or equal to 1 . The correction coefficient considers the change in performance of the collection device diffuser caused by the swirling flow at the outlet of the runner, the blade tip vortices, and the hub. It also considers the entrance loss of the collection device, which has been ignored thus far.

Figures 16-18 show the correlation between the tip speed ratio $\lambda$ and, respectively, the diffuser pressure recovery coefficient $C_{\mathrm{pd}}$, the correction coefficient $f$, and the backpressure coefficient $C_{\mathrm{pb}}$. In addition, the static pressure distribution and streamlines for the composite body for the tip speed ratio $\lambda=6.5$ are shown in Figures 19 and 20, respectively. Although $C_{\mathrm{pd}}$ for the composite body increases with increasing $\lambda$, except for high tip speed ratios (Figure 16), it is smaller than the $C_{\mathrm{pd}}$ for the collection device. From Figures 19 and 20, we see that the runner outlet flow is nonuniform, which can explain why the diffuser performance deteriorated. From Figure 17, $f$ for the composite body increases with increasing $\lambda$ and approaches $1 . K$ decreases with increasing $\lambda$, as shown in Figure 14, which is attributed to the reduced entrance loss in the collection device. From Figure 18, the $C_{\mathrm{pb}}$ for the composite body is greater than the $C_{\mathrm{pb}}$ for the collection device and increases with increasing $\lambda$. This is explained as follows: in the composite body, the runner acts as resistance and static pressure increases immediately in front of the runner, as shown in Figure 19. This is the reason why the flow, as in the case of the collection device, does not enter the collection device inlet smoothly and, in the case of the composite body, is partially excluded outside the inlet to the collection device (Figure 20). Because the excluded flow prevents the external flow toward the brim, the vortex formation owing to the brim weakens more as $\psi$ increases for high tip speed ratios, which presumably makes the backpressure drop more difficult. However, the streamlines are not displayed at the lower part of the runner's wake, because the flow is strongly three-dimensional in this region.

Next, we study the $K$ for the collection device in the composite body for $\psi=0$. Using $C_{\mathrm{pd}}, f$, and $C_{\mathrm{pb}}$ for the composite body with $\lambda=6.5$, we obtain $K=1.974$ from (3). The value of $K$ for the collection device in the composite body is close to $K=2.241$ for the collection device on its own. It follows that for $\lambda=6.5$ approximately $75.6 \%$ of the significant reduction with respect to the collection device in $K$ for the composite body is only the loading coefficient, that is, the effect of the resistance of the runner itself. We find that the remaining approximately $24.4 \%$ is the effect of the change in the performance of the collection device owing to the installation of the runner.

From the above considerations, the inlet velocity ratio is significantly lower for the composite body (comprising the collection device appended to the runner) than for the single collection device. This reduction is caused by the resistance of the runner itself, the decreased diffuser pressure recovery coefficient, and the increased backpressure coefficient. However, with the tip speed ratio for maximum output, the inlet velocity ratio and loading coefficient of the composite body increases compared with the runner. In particular, the input power coefficient increases significantly owing to the increase in the inlet velocity ratio. Therefore, although the turbine efficiency is roughly the same, we find that the power coefficient of the composite body increases to approximately 2.76 times that of the runner.

\section{Verification Test}

To verify the effectiveness of the hydraulic turbine, we performed a test in the canal in Tadamimachi in the Minamiaizu District of Fukushima prefecture. The prototype used in 


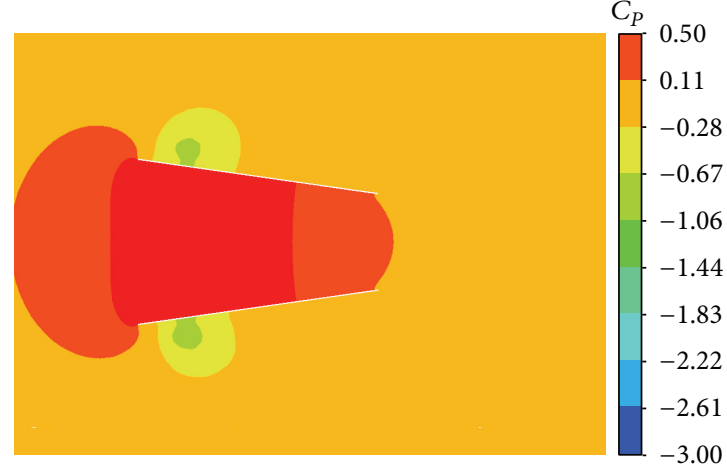

(a) Type A

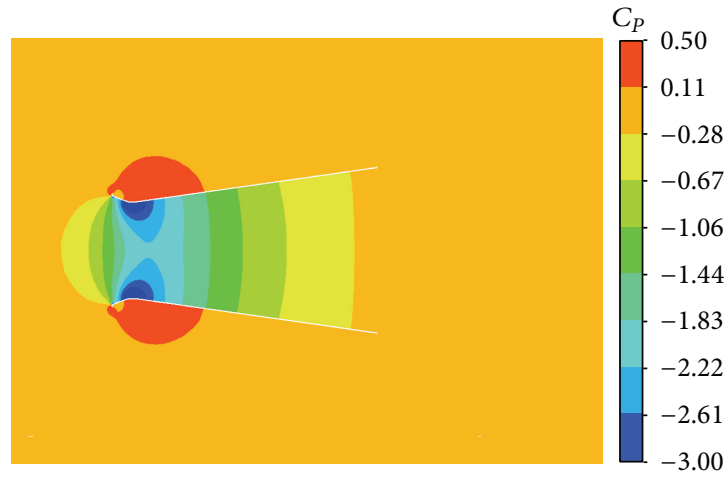

(c) Type C

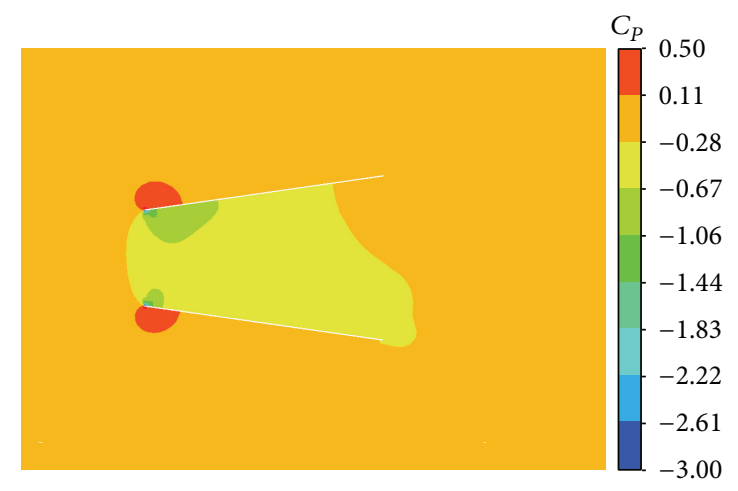

(b) Type B

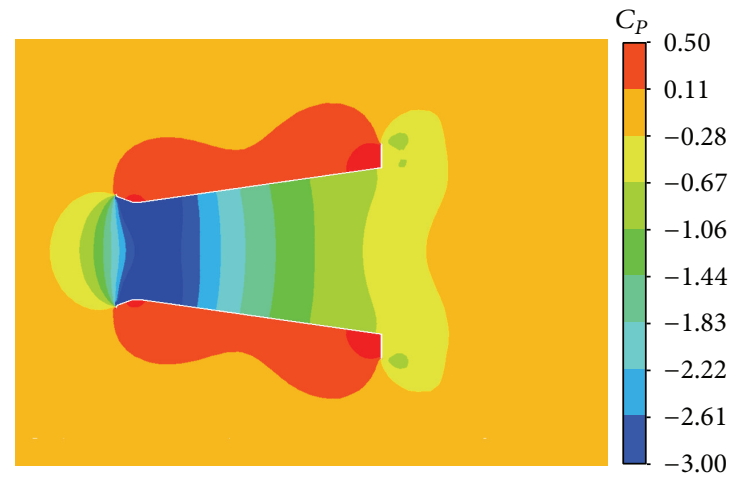

(d) Type D

FIGURE 8: Static pressure distributions.

the verification test, as well as the test setup environment, is shown in Figures 21 and 22, respectively. The working prototype comprises the runner, the collection device (type D), and the generator. The various elements of the runner and the collection device are generally the same as those previously described for the computational model. The width of the conduit of the open channel was about $1900 \mathrm{~mm}$ and the water depth was about $570 \mathrm{~mm}$. The open-channel flow velocity was measured with a propeller meter $380 \mathrm{~mm}$ upstream of the turbine, before the turbine was placed. The average flow velocity, found using the two-point method, was $1.72 \mathrm{~m} / \mathrm{s}$.

The actual value for the output power $W$ obtained from the verification test is shown in Figure 23. It is shown together with the value of $W$ calculated from $C_{W}$ of the composite body for $v_{\infty}=1.72 \mathrm{~m} / \mathrm{s}$. However, the measured value of $W$ is the value found by adding the actual inverter loss, power transmission loss, and generator loss, which are all measured beforehand, to the inverter output power. Figure 23 shows that the actual and calculated values agree relatively well. Moreover, the actually measured value reaches approximately 156.4 $\mathrm{W}$ for $n=496 \mathrm{~min}^{-1}$. The difference between the measured and calculated values can be accounted as follows: (1) by not measuring the average flow velocity in the verification test for the open-channel flow; (2) by not considering in the numerical analysis either the effect of the free surface and velocity distribution for the open-channel flow or the form of the power transmission mechanism. These effects are the subject of future studies.

\section{Conclusions}

We have proposed a new portable hydraulic turbine with a unique collection device, which uses the kinetic energy of flow in open channels. The performance of the turbine's runner, the collection device, and the composite body comprising the collection device and runner and their respective flow fields were all studied by using numerical analysis. Moreover, the results of a verification test in a real canal suggested the following.

(1) The static pressure increases near the inlet of the nozzle-type collection device and hinders the flow from entering the collection device. On the other hand, the static pressure near the diffuser type collection device decreases and the flow easily moves into it.

(2) Adding an inlet nozzle to the diffuser-type collection device helps the flow to enter smoothly and suppresses the backflow inside the collection device. Thus, there was a significant increase in the diffuser pressure recovery coefficient and the inlet velocity ratio. 


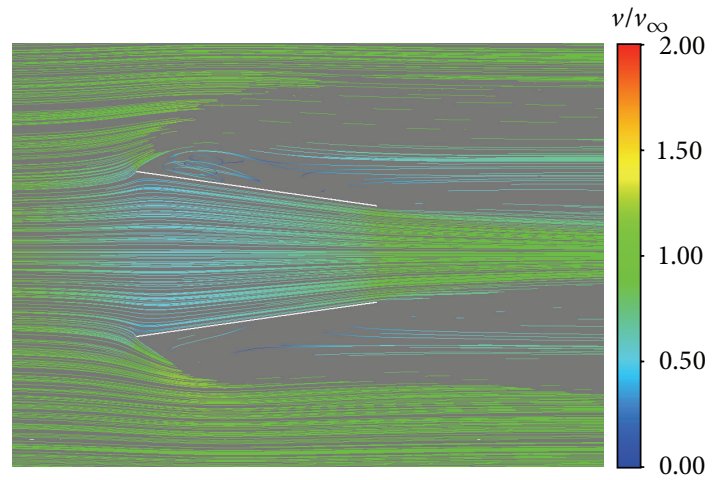

(a) Type A

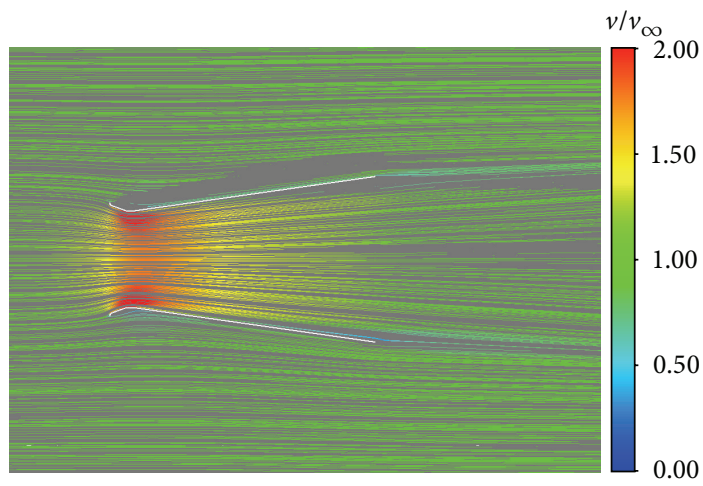

(c) Type C

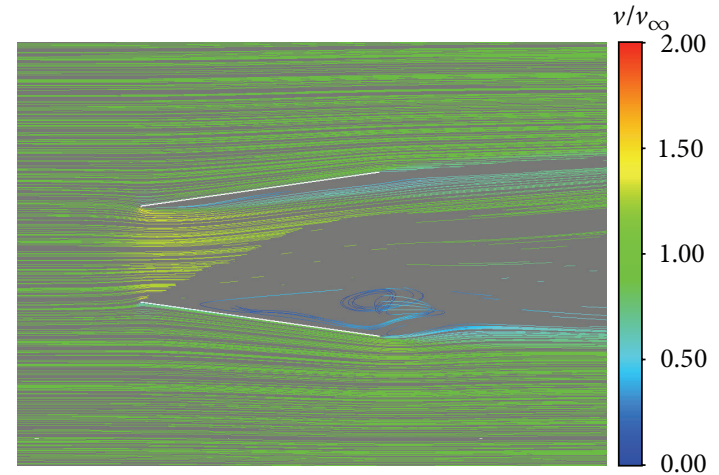

(b) Type B

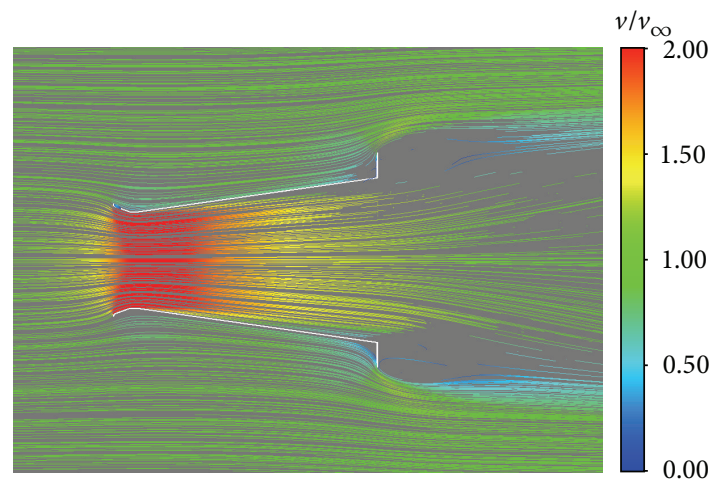

(d) Type D

Figure 9: Streamlines.

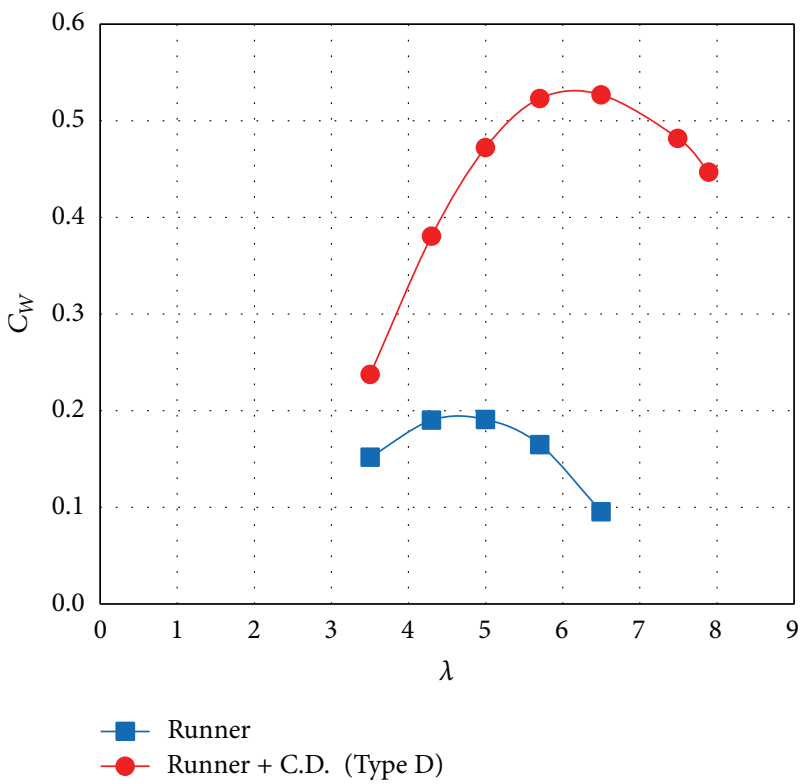

FIGURE 10: Correlation between the tip speed ratio and the power coefficient.

(3) Adding a brim to the diffuser-type collection device, which has an attached inlet nozzle, created a largescale separation vortex to the rear of the brim; thus, the backpressure coefficient greatly decreased. Consequently, the inlet velocity ratio for the collection device was maximized and a ratio of 2.241 was achieved.

(4) At the tip speed ratio yielding the maximum output power, the inlet velocity ratio and loading coefficient of the composite body (comprising the runner and the collection device) were approximately $31 \%$ and $22 \%$ higher, respectively, for the composite body than for the runner. In particular, the input power coefficient significantly increased (by approximately 2.76 times), on account of the higher inlet velocity ratio. For this reason, although the turbine efficiency was almost the same, the power coefficient increased to approximately 2.76 times that for the runner.

(5) The inlet velocity ratio is significantly lower for the composite body than for the single collection device. This reduction is caused by the resistance of the runner itself, the decreased diffuser pressure recovery coefficient, and the increased backpressure coefficient.

(6) For the working prototype (with a runner outer diameter of $380 \mathrm{~mm}$ ), the achieved turbine output power was verified as being approximately $156.4 \mathrm{~W}$ when the rotational speed was $496 \mathrm{~min}^{-1}$ for an 


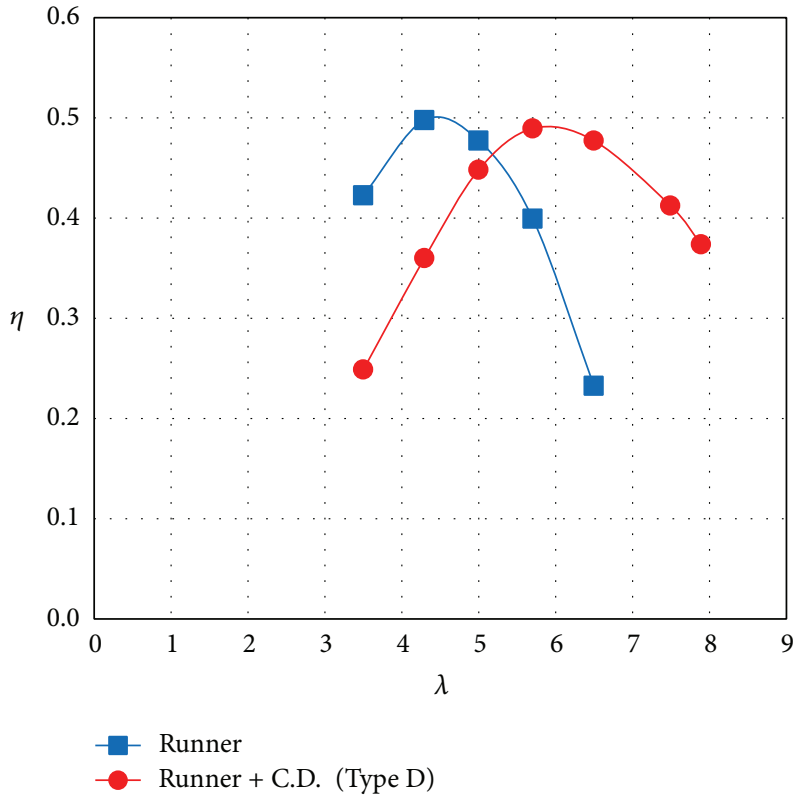

FIGURE 11: Correlation between the tip speed ratio and the turbine efficiency.

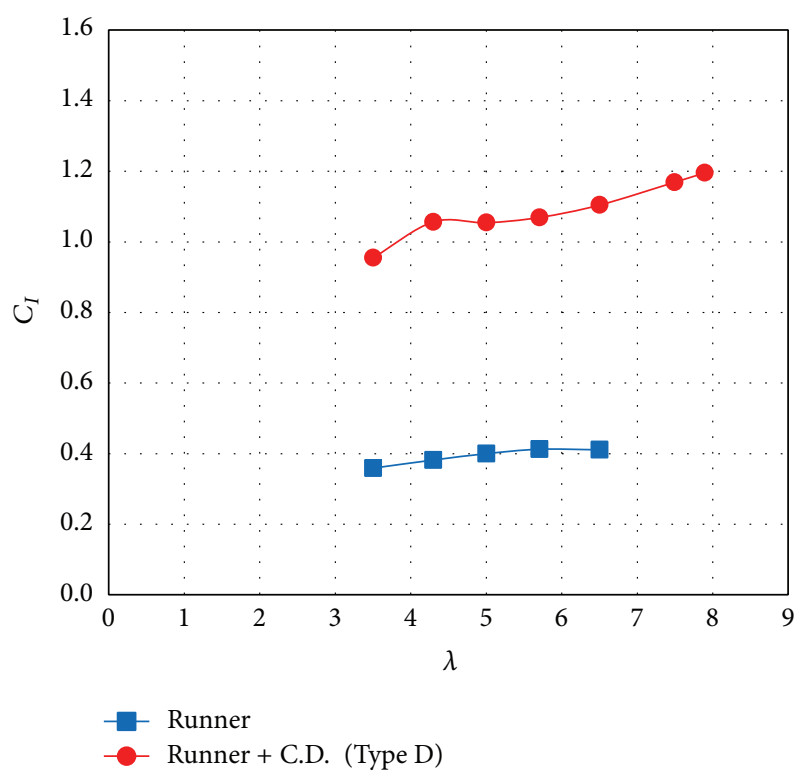

FIgURE 12: Correlation between the tip speed ratio and the input power coefficient.

average flow velocity of $1.72 \mathrm{~m} / \mathrm{s}$ and a water depth of $530 \mathrm{~mm}$.

\section{Nomenclature}

A: Water-receiving area $\mathrm{m}^{2}=\pi r_{t}^{2}$

$C_{I}$ : Input power coefficient

$=\left(\overline{P_{1}}-\overline{P_{2}}\right) Q /\left(\rho A v_{\infty}^{3} / 2\right)$

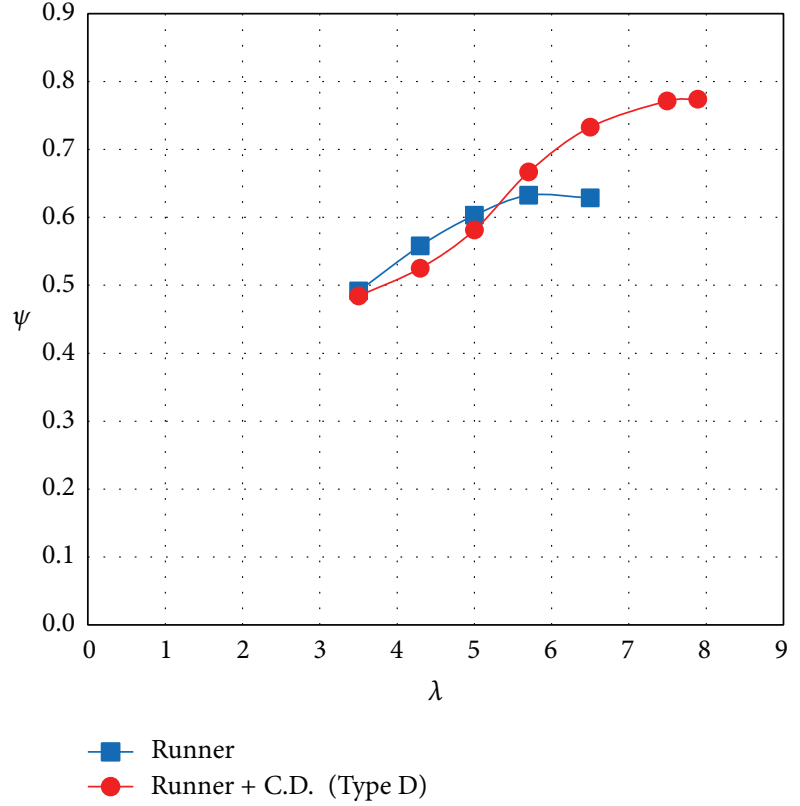

FIGURE 13: Correlation between the tip speed ratio and the loading coefficient.

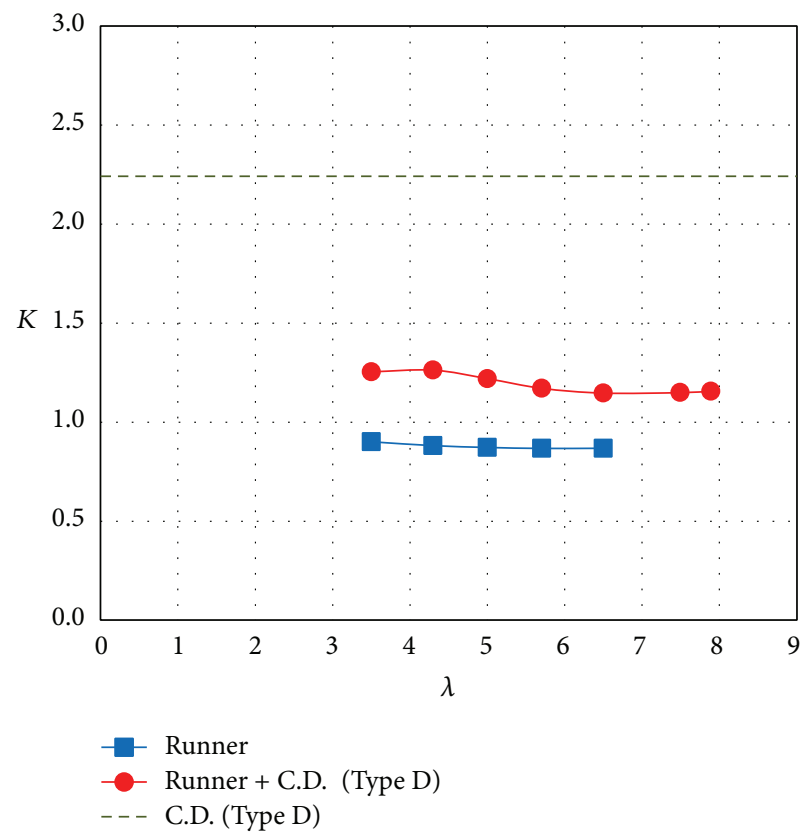

FIGURE 14: Correlation between the tip speed ratio and the inlet velocity ratio.

$C_{P}:$ Pressure coefficient $=\left(P-P_{\infty}\right) /\left(\rho v_{\infty}^{2} / 2\right)$

$C_{\mathrm{pb}}$ : Backpressure coefficient

$=\left(\overline{P_{3}}-P_{\infty}\right) /\left(\rho v_{\infty}^{2} / 2\right)$

$C_{\mathrm{pd}}:$ Diffuser pressure recovery coefficient

$=\left(\overline{P_{3}}-\overline{P_{2}}\right) /\left(\rho{\overline{v_{a 1}}}^{2} / 2\right)$

$C_{W}$ : Power coefficient $=W /\left(\rho A v_{\infty}^{3} / 2\right)$

$f:$ Correction coefficient

$h$ : Brim length $\mathrm{m}$ 


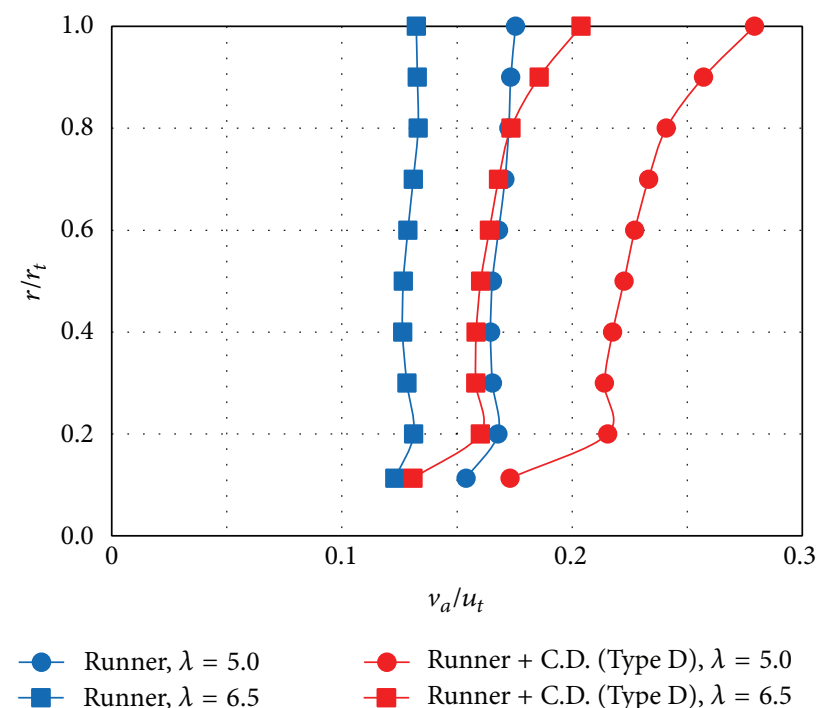

FIgURE 15: Radial distributions of the axial component of the absolute velocity at the runner inlet.

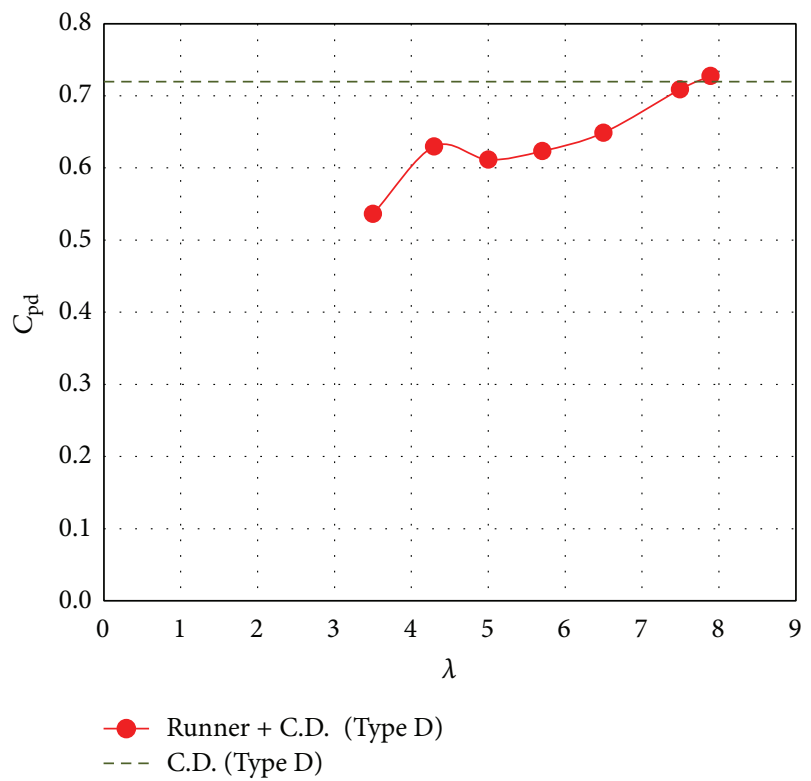

FIGURE 16: Correlation between the tip speed ratio and the diffuser pressure recovery coefficient.

$K:$ Inlet velocity ratio $=\overline{v_{a 1}} / v_{\infty}$

$n$ : Rotational speed $\min ^{-1}$

$P$ : Static pressure (gauge pressure) $\mathrm{Pa}$

Q: Flow rate through the runner $\mathrm{m}^{3} / s=A \overline{v_{a 1}}$

$r$ : Runner radius $\mathrm{m}$

v: Absolute velocity $\mathrm{m} / \mathrm{s}$

$W$ : Output power $\mathrm{W}$

$x$ : Distance in the $x$ direction $\mathrm{m}$

$x_{l}$ : Collection device total length $\mathrm{m}$.

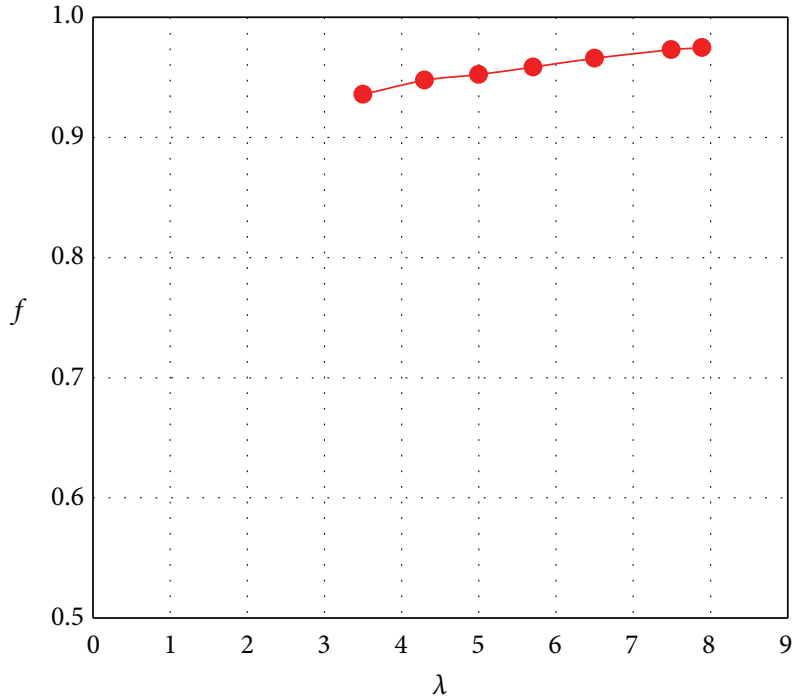

- Runner + C.D. (Type D)

FIGURE 17: Correlation between the tip speed ratio and the correction coefficient.

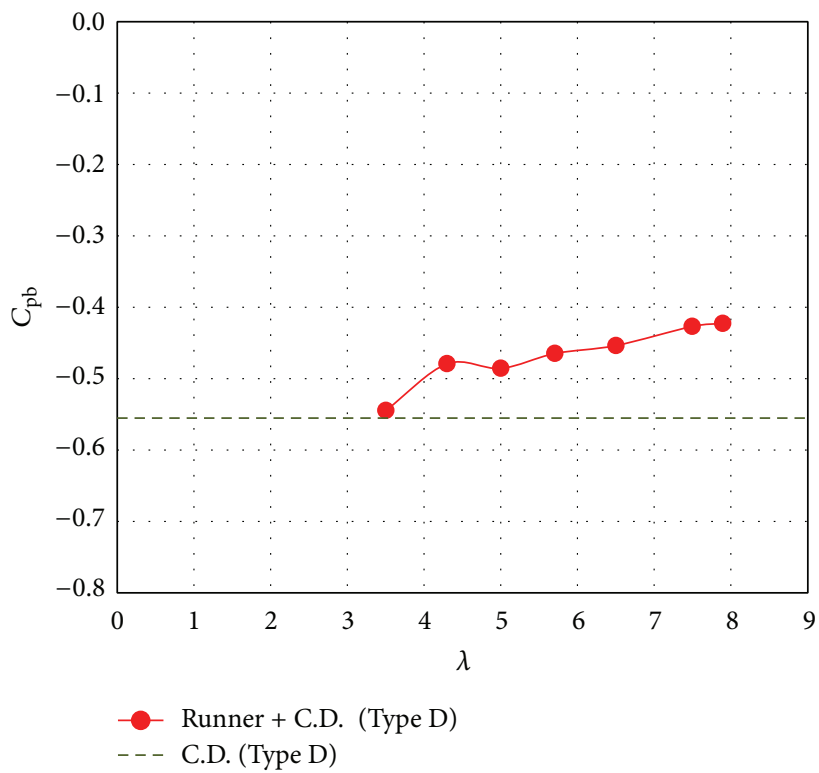

FIGURE 18: Correlation between the tip speed ratio and the backpressure coefficient.

\section{Greek Letters}

$\eta$ : Turbine efficiency $=C_{W} / C_{I}$

$\lambda$ : Tip speed ratio $=r_{t} \omega / v_{\infty}$

$v:$ Hub ratio $=r_{h} / r_{t}$

$\rho$ : Fluid density $\mathrm{kg} / \mathrm{m}^{3}$

$\psi$ : Loading coefficient $=\left(\overline{P_{1}}-\overline{P_{2}}\right) /\left(\rho{\overline{v_{a 1}}}^{2} / 2\right)$

$\omega:$ Rotational angular velocity $\mathrm{rad} / \mathrm{s}$. 


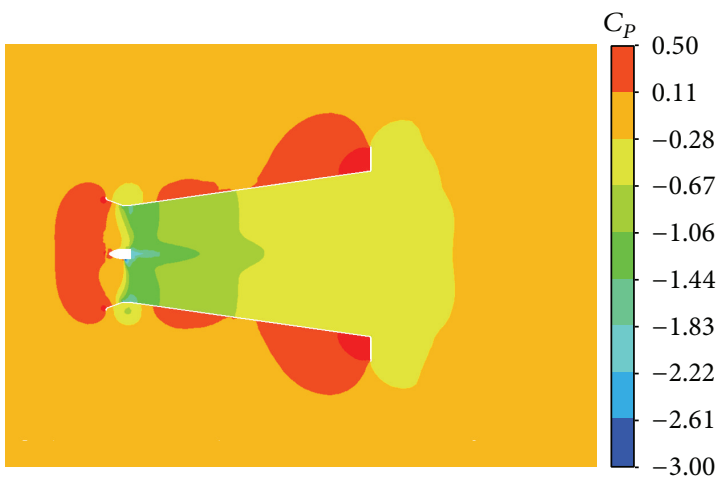

FIGURE 19: Static pressure distribution at $\lambda=6.5$ (Runner + C.D. (Type D)).

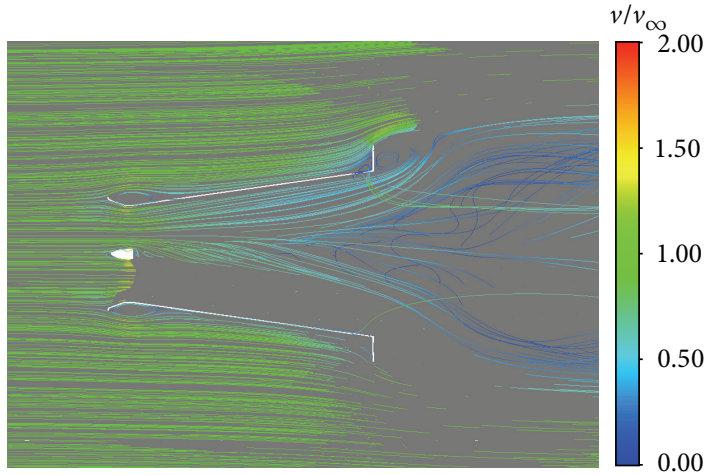

Figure 20: Streamline $\lambda=6.5$ (Runner + C.D. (Type D)).

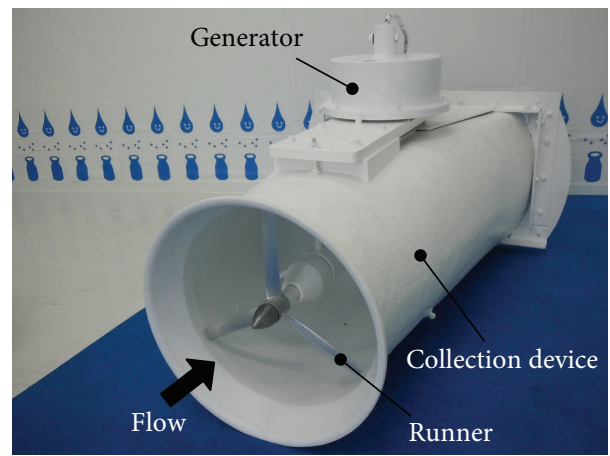

Figure 21: Prototype.

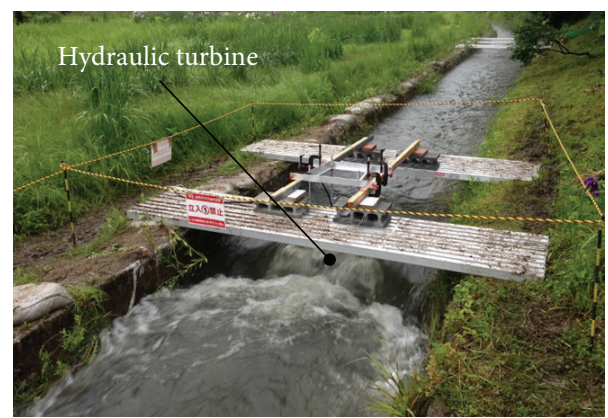

Figure 22: The situation of verification test.

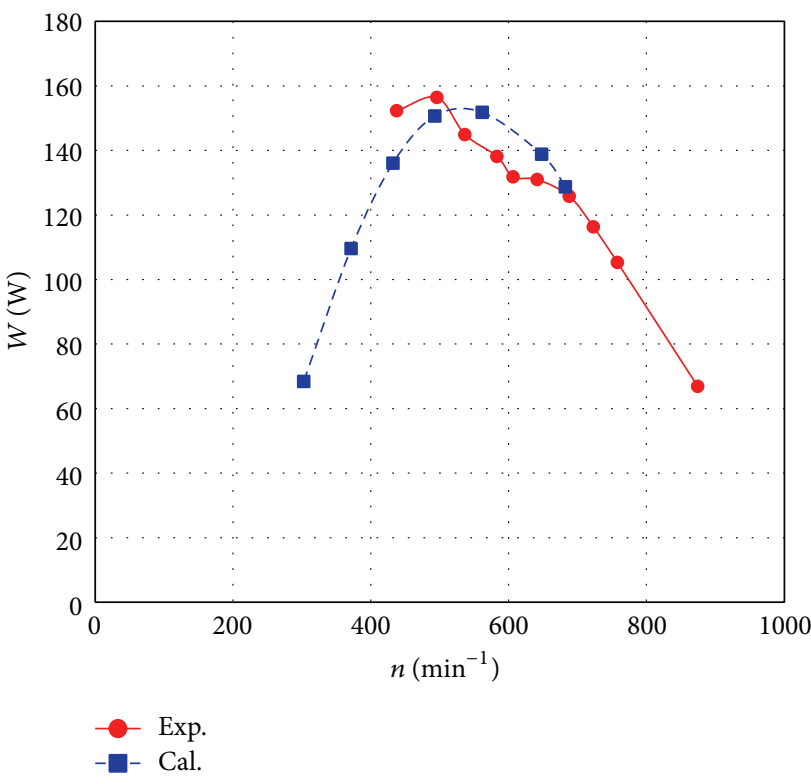

FIGURE 23: Correlation between the rotational speed and the output power.

\section{Subscripts}

1: Just before the runner

2: Just after the runner

3: Collection device outlet

a: Axial component

$h, t:$ Hub, tip

$\infty$ : Infinite distance

-: Average value for the flow rate.

\section{Conflict of Interests}

The authors declare that there is no conflict of interests regarding the publication of this paper.

\section{References}

[1] T. S. Reynolds, Stronger than A Hundred Men: A History of the Vertical Water Wheel, The Johns Hopkins University Press, 1983.

[2] Y. Fujiwara, H. Kado, and Y. Hosokawa, "History and performance of traditional water wheel in western Europe," Transactions of the Japan Society of Mechanical Engineers, vol. 90, no. 819, pp. 212-218, 1987.

[3] D. Capecchi, "Over and undershot waterwheels in the 18th century. Science-technology controversy," Advances in Historical Studies, vol. 2, no. 3, pp. 131-139, 2013.

[4] M. Anyi and B. Kirke, "Evaluation of small axial flow hydrokinetic turbines for remote communities," Energy for Sustainable Development, vol. 14, no. 2, pp. 110-116, 2010.

[5] A. Inagaki and T. Kanemoto, "Performance of Gyro-type hydraulic turbine suitable for shallow stream," Turbomachinery, vol. 33, no. 10, pp. 614-621, 2005.

[6] M. Nakajima, S. Iio, and T. Ikeda, "Performance of savonius rotor for environmentally friendly hydraulic turbine," Journal of Fluid Science and Technology, vol. 3, no. 3, pp. 420-429, 2008. 
[7] M. Inoue, A. Sakurai, and Y. Ohya, "A simple theory of wind turibine with Brimmed diffuser," Turbomachinery, vol. 30, no. 8, pp. 497-502, 2002.

[8] Y. Ohya, T. Karasudani, and A. Sakurai, "Development of highperformance wind turbine with brimmed diffuser," Journal of the Japan Society for Aeronautical and Space Sciences, vol. 50, no. 587, pp. 477-482, 2002.

[9] K. Abe, M. Nishida, A. Sakurai et al., "Experimental and numerical investigations of flow fields behind a small wind turbine with a flanged diffuser," Journal of Wind Engineering and Industrial Aerodynamics, vol. 93, no. 12, pp. 951-970, 2005.

[10] K. Toshimitsu, K. Nishikawa, W. Haruki, S. Oono, M. Takao, and Y. Ohya, "PIV measurements of flows around the wind turbines with a flanged-diffuser shroud," Journal of Thermal Science, vol. 17, no. 4, pp. 375-380, 2008.

[11] Y. Ohya and T. Karasudani, "A shrouded wind turbine generating high output power with wind-lens technology," Energies, vol. 3, no. 4, pp. 634-649, 2010.

[12] M. J. Khan, G. Bhuyan, M. T. Iqbal, and J. E. Quaicoe, "Hydrokinetic energy conversion systems and assessment of horizontal and vertical axis turbines for river and tidal applications: a technology status review," Applied Energy, vol. 86, no. 10, pp. 1823-1835, 2009.

[13] D. L. F. Gaden and E. L. Bibeau, "A numerical investigation into the effect of diffusers on the performance of hydro kinetic turbines using a validated momentum source turbine model," Renewable Energy, vol. 35, no. 6, pp. 1152-1158, 2010.

[14] B. Cui, Z. Song, Y. Zhang, Y. Jin, and Y. Lin, "Influence of additional device on performance of the marine current turbine," Open Journal of Fluid Dynamics, vol. 2, pp. 305-310, 2012.

[15] H. Sun and Y. Kyozuka, "Experimental validation and numerical simulation evaluation of a shrouded tidal current turbine," Journal of the Japan Society of Naval Architects and Ocean Engineers, vol. 16, pp. 25-32, 2012.

[16] H. Matsumiya, T. Kogaki, M. Iida, and K. Kieda, "Development of a high performance airfoil," Turbomachinery, vol. 29, no. 9, pp. 519-524, 2001.

[17] ANSYS, ANSYS CFX-Solver Modeling Guide, ANSYS, Inc., Canonsburg, Pa, USA, 2010. 

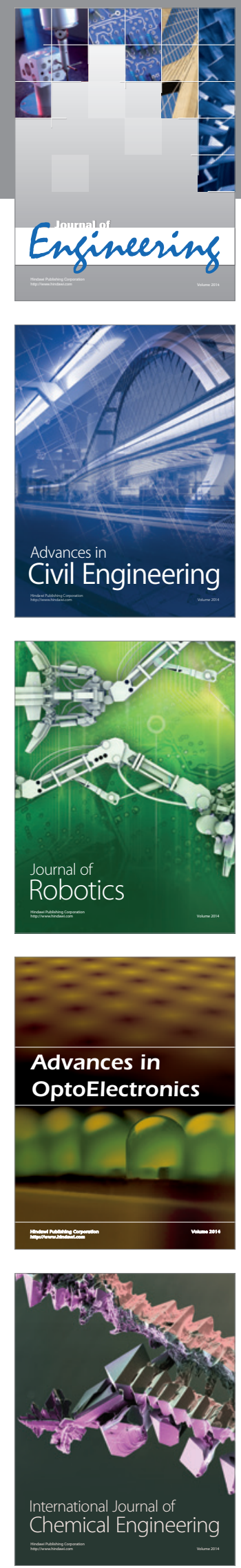

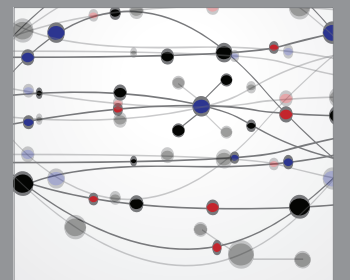

The Scientific World Journal
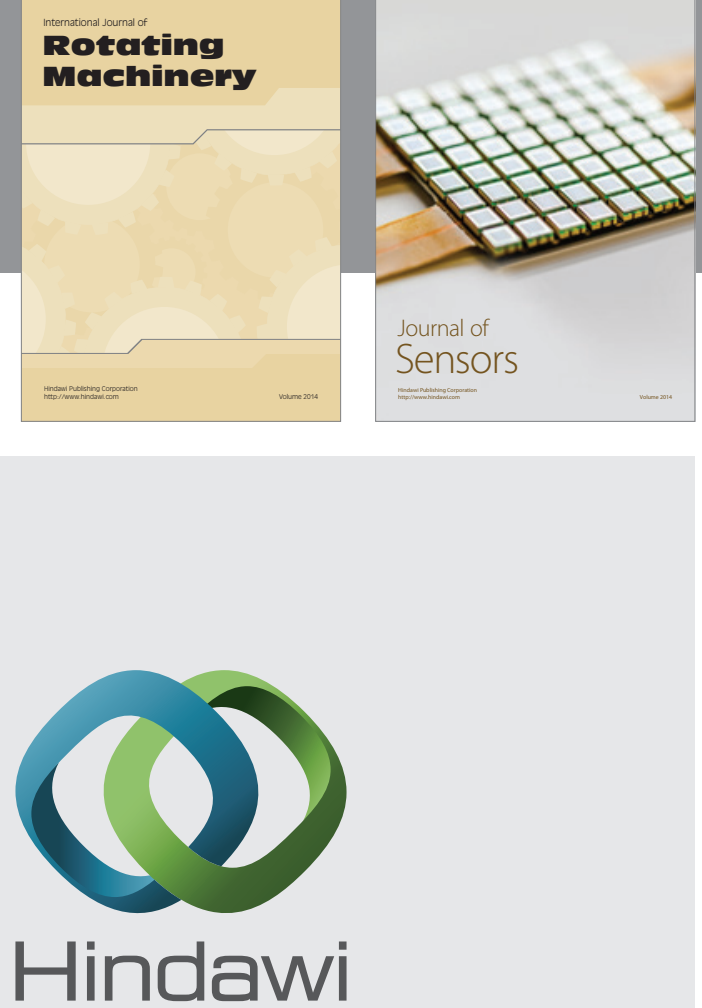

Submit your manuscripts at http://www.hindawi.com
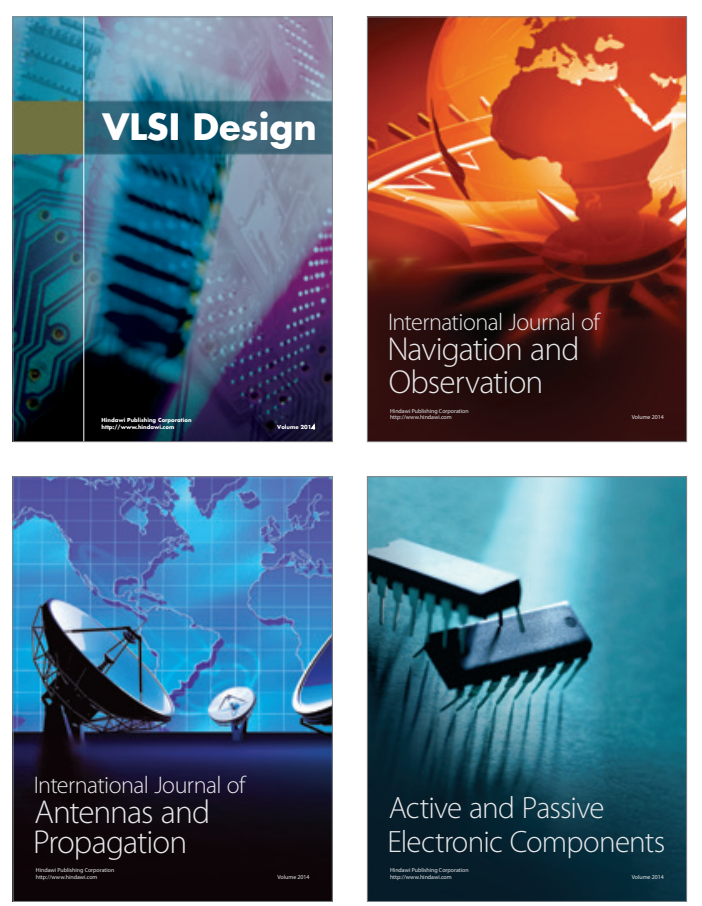
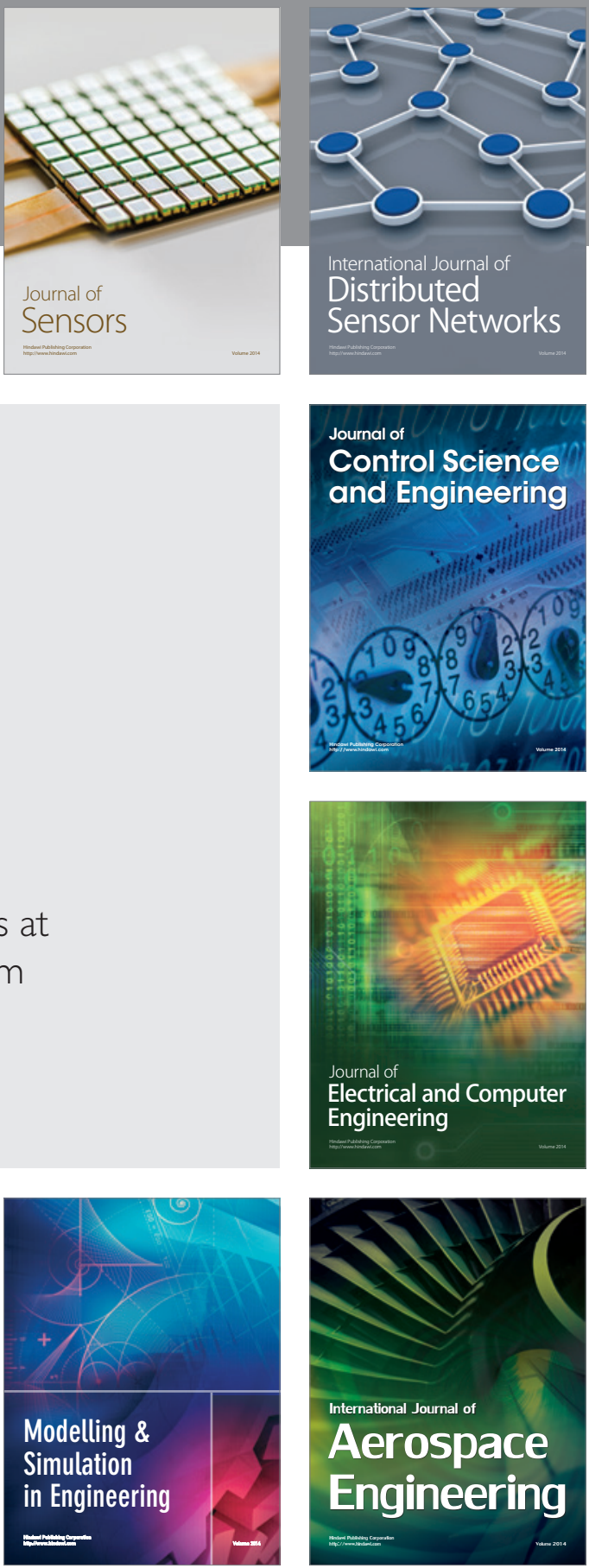

Journal of

Control Science

and Engineering
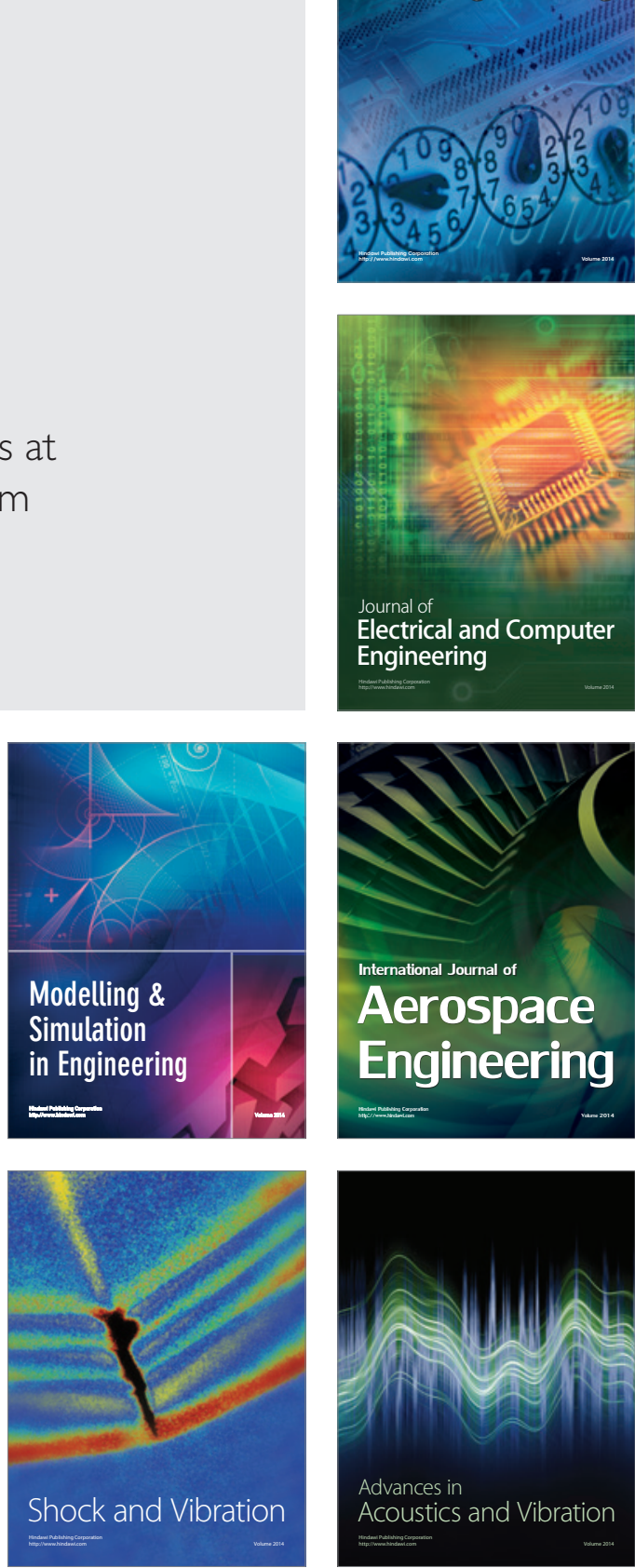